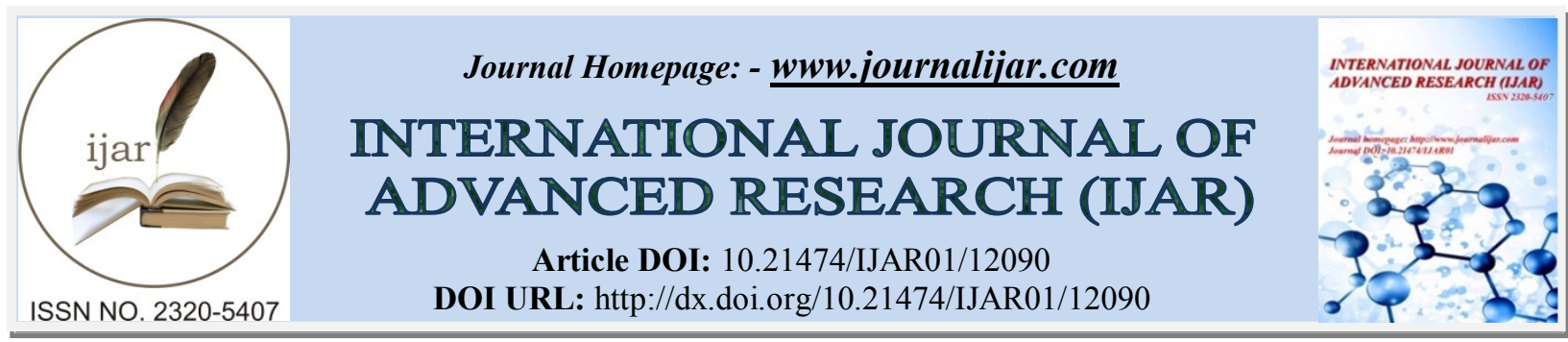

RESEARCH ARTICLE

\title{
AN EXCEPTIONAL CASE OF A POSTERIOR PURE OPEN DISLOCATION OF THE ELBOW WITH RUPTURE OF THE BRACHIAL ARTERY
}

\author{
Hicham Benomar ${ }^{1}$, Mohamed Boussaidane ${ }^{1}$, Tamdy Adil ${ }^{1}$, Abdelhay Rabah ${ }^{1}$, Jalal El Mekkaoui ${ }^{1}$, Jalal \\ Boukhris $^{1}$, Driss Benchebba ${ }^{1}$, Mostapha Boussouga ${ }^{1}$, Mohamed Zoulati ${ }^{2}$, Hassan Chtata ${ }^{2}$ and Mustafa \\ Taberkant ${ }^{2}$ \\ 1. Department of Orthopedic A Traumatological Surgery, Mohamed V Military Hospital, Rabat-Morocco. \\ 2. Department of Vascular Surgery, Mohamed V Military Hospital, Rabat-Morocco.
}

\section{Manuscript Info}

.........................

Manuscript History

Received: 25 September 2020

Final Accepted: 28 October 2020

Published: November 2020

Key words:-

Open Pure Elbow Dislocation-Brachial Artery Rupture- Venous Graft-Humeral Pin

\section{Abstract}

Pure open dislocation of the elbow remains a very rare entity, being associated with a complete rupture of the brachial artery make it more exceptional, the therapeutic strategy is very discussed. The vascular repair is essentially based on a venous graft which can be collected from different sites, the second challenge is to reduce and maintain the stability of the elbow. The course ofthis different operatory times represents the real challenge in front of that type of traumas. We report a case of a young man admitted in the emergency room with an open pure elbow dislocation with rupture of the brachial artery, treated by a venous graft and reparation of the elbow capsular with an elbow immobilization by an ulno-humeral pin and with a satisfactory evolution in a long term.

Copy Right, IJAR, 2020,. All rights reserved.

\section{Introduction:-}

In order of frequency, elbow dislocations mainly occur after shoulder dislocations [1]. Its prognosis is usually good. This trauma is exceptionally open [1]. The anatomical proximity of the neurovascular structures could be responsible of associated lesions which turn out to be very rare. Currently there is still no consensus for a management of these traumas [2].

We herein report a rare situation of a 19-year-old patient with a pure open dislocation of the left elbow associated with brachial artery rupture.

\section{Case Report:}

A 19-year-old young man, right handed, with no medical history, was admitted to the emergency room for an open trauma of the upper left limb that occurred during a high-energy road traffic accident.

The patient was admitted 2 hours after his accident, after conditioning, the clinical examination revealed a wound in the fold of the left elbow with protruding bone figure 1.The vasculo-nervous examination found a cold limb with abolition of both radial and ulnar pulses and a sensory-motor deficit concerning the territories the median and ulnar nerves.

Corresponding Author:- Hicham Benomar Address:- Department of orthopedic a traumatological surgery, Mohamed V military hospital, RabatMorocco. 
Imaging: standard radiography and computed tomography showed a pure posterior dislocation of the left elbowfigures 2 and 3. The patient was taken to the operating room where surgical exploration revealed an open posterior dislocation of the left elbow, a rupture of the brachialis muscle, a rupture of the joint capsule and finally a rupture of the brachial artery at its bifurcation. The radial and the median nerves were macroscopically intact but the latter had been elongated by the humeral condyle during dislocation. After surgical trimming, we proceeded to the reduction of the dislocation, it should be noted that the elbow remained unstable at $30^{\circ}$, before passing to the time of vascular repair which was made by venous graft by the homolateral internal saphenous veinfigure 4 . We then finished by repairing the joint capsule and the brachialis muscle and immobilizing the elbow by arthrorise with an ulno-humeral pin at $60^{\circ}$ of flexion figure 5. The patient was put on antibiotic prophylaxis and we protect the elbow by a plastered brachio-antebrachio-palmar splint.

Immediate post-operative follow-up was satisfactory with a warm limb and both radial and ulnar pulses were perceived, the patient was allowed to leave the hospital after the 5th day, the ulno-humeral spin was removed after 3 weeks, the elbow remains stable at $30^{\circ}$ of extension, the patient was authorized to begin passive functional rehabilitation, however the patient retained minimal motor deficit as well as a slight sensory deficit, affecting the territories of both ulnar and median nerves. After a 6 weeks follow-up, the elbow extension was at $-60^{\circ}$ and the flexion at $90^{\circ}$, an electromyogram revealed an axonotmesis of both median and ulnar nerve. After 18 months we noticed an improvement in extension with only a $20^{\circ}$ deficit, the extension was complete and the pronosupination of the forearm was recovered

\section{Discussion:-}

The frequency of elbow dislocation associated to vascular involvement, especially in the event of opening dislocation, remains difficult to establish, the literature only reports short series of sporadic clinical cases [1].

Endan and al [1,2] observed eight arterial lesions in 63 elbow dislocations, representing a prevalence of $12,7 \%$ Dislocations of the elbow occur when falling on the hand, the elbow is in extension or slight flexion, two lesionals mechanisms are to be described: hyper-extension, which is responsible for a rupture of the anterior capsular and muscular plane, and the association of a valgus supination constraint and axial compression which for its part is at the origin of sequential circumferential lesions which go from the lateral ligament complex towards the medial ligament complex $[1,3,4,5,6,7]$.

Currently the recommended attitude towards a simple dislocation of the elbow once its reduction is done is to test the frontal stability as well as its propensity for recurrence in the last degrees of extension; only ruptured ligament structures that generate reduction instability are repaired.[7,10,11,12].

In the event of closed or open dislocations and with restoration of the vascular axis, the concomitant ligament repair could be discussed because the anteromedial approach of the pedicle gives access at least to the ulnar capsuloligamentary plane. Thus, for all the authors the stability of the elbow after reduction was the determining element of orthopedic management and was not different from that simple dislocations. The clinical result is most often favorable in the medium term for closed dislocations, apart from a sequelae stiffness essentially in extension $[1,8,9,13,14,15,16]$. The open nature of dislocation adversely affects the course, this may be due to associated lesions like those reported by Louis and al [14].

Arterial interruption may be as clinically evident as the dislocation that produced it, with abolition of the pulse and paleness of the hand however it may be less evident even after reduction due to incomplete thrombus [19] or because of the supply of rich collateral [17]. Arteriography, standard examination after reduction of dislocation is urgently required, with the slightest clinical doubt $[1,16,20]$.

Grimer and Brooks [17] underlined the value of Doppler after reduction, which is reliable and less invasive than the CT angiography, that is simple to perform, but indicated for polytrauma victims

Concurrent damage to the median and/or ulnar nerve(s) is logical given their proximity to the vascular axis [1]. At the clinical stage and especially in case of prolonged ischemia, their diagnosis is difficult because the paralytic syndrome is part of the manifestations of complete vascular interruption, otherwise the diagnosis of neurological damage is much simpler by evidence of a sensory and/or motor deficit in the neurological territory to the median and ulnar nerve [1]. 
The surgical attitude comes down to responding to two main problems: the restoration of vascular continuity and joint stabilization. Vascular repair can only be conceived on a reduced elbow and it must remain reduced in its functional position $[1,2,5]$. The arterial lesions encountered are: complete or sub-adventitial rupture, incarceration and thrombosis [1]. The vascular repair will depend on the arterial lesion: direct suturing on the event of a clear section and total integrity of the underlying and above walls [15,17,], or reverse bypass by a graft from the great saphenous vein $[1,15,17$,$] . Rignault and Moine[13] insisted on the existence of intimal lesion extending at a distance$ from the rupture in the arterial contusions imposing a cut in a healthy zone to avoid the risk pf secondary thrombosis. In addition, the vascular gesture being done in flexion, its necessary to foresee the future tension on the arterial trunk repaired during the extension of the elbow. The great saphenous vein remains an ideal solution. Discharge aponeurotomy are necessary in the presence of compartment syndrome, severe tissue and venous trauma, and for some after ischemia lasting more than four hours $[1,15,20,21]$.

In case of open dislocation, the therapeutic regimen is classic: the elbow is reduced then trimmed and explored for confirmation of the diagnosis and evaluation of the lesions. Immobilization by fixative remains the best option: during its installation, the saphenous graft is taken, the elbow fixed around $90^{\circ}$ and stable allows the safe completion of the bypass. A repair the ulnar ligament complex by direct suturing or intra-osseous anchor could precede this gesture [6,11]. The antebrachial discharge incisions should be made in the event of late revascularization or complete ischemia with a very edematous forearm [1]. The elbow is considered stable if the dislocation only recurs in the last degrees of extension [1].

\section{Liste of figures:}

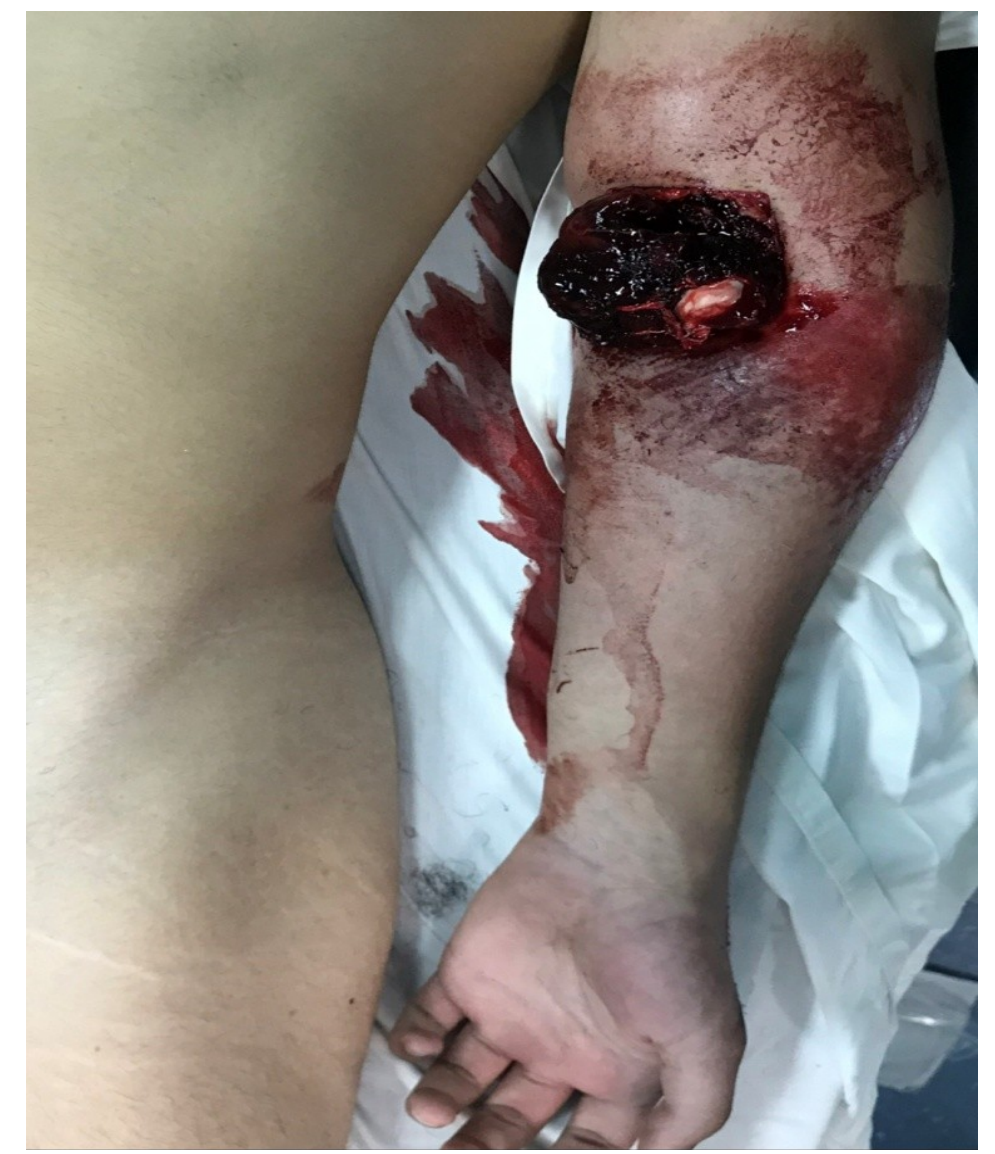

Figure 1:- A wound in the fold of the left elbow with protruding bone. 


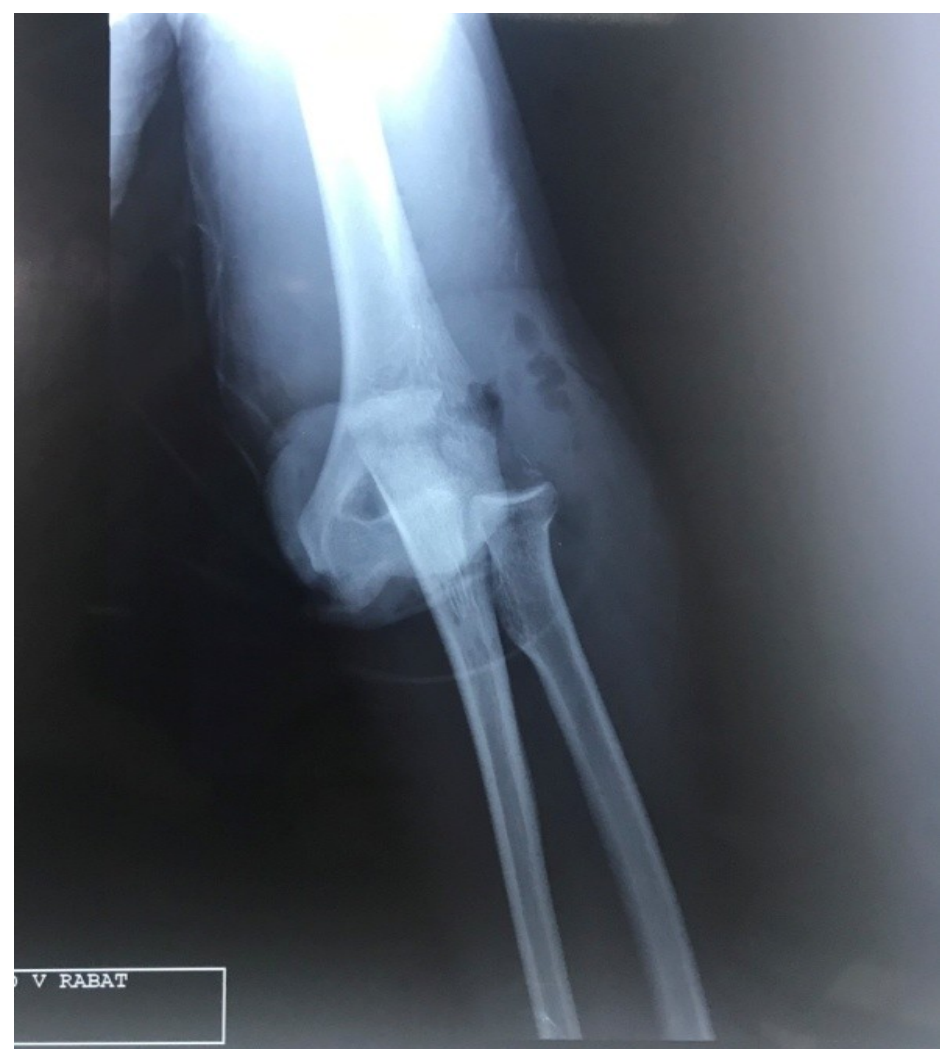

Figure 2:- Standard radiography of the left elbow showing the dislocation.

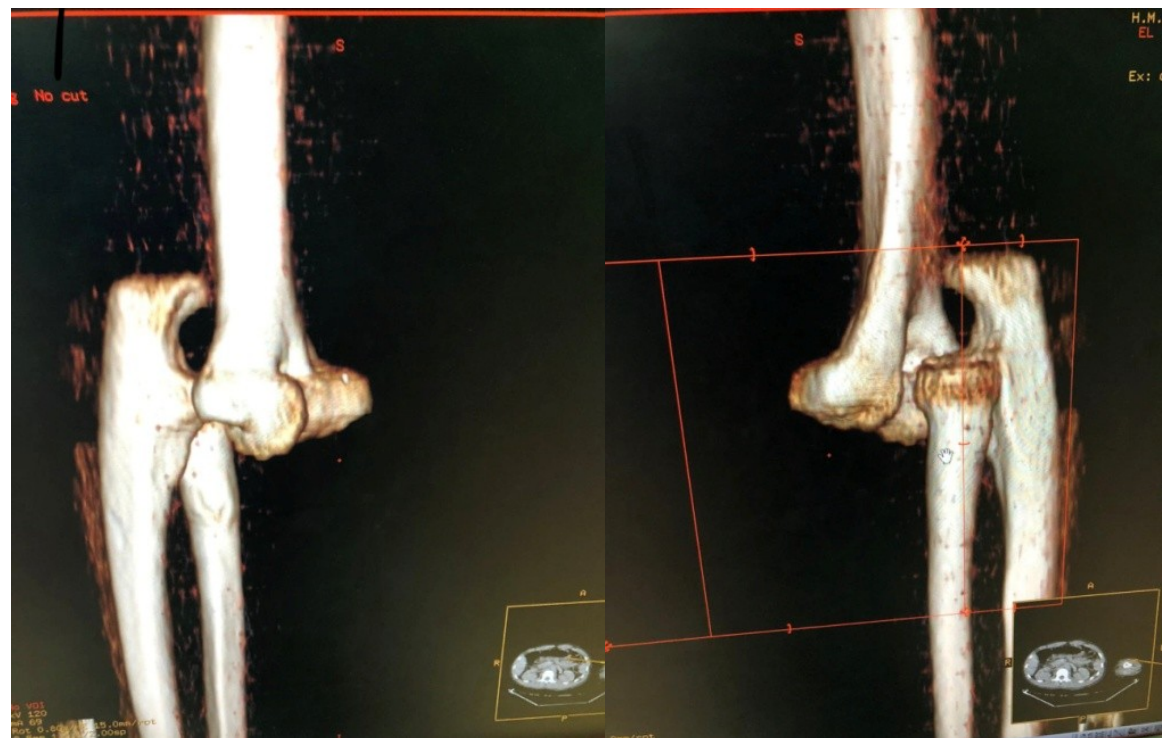




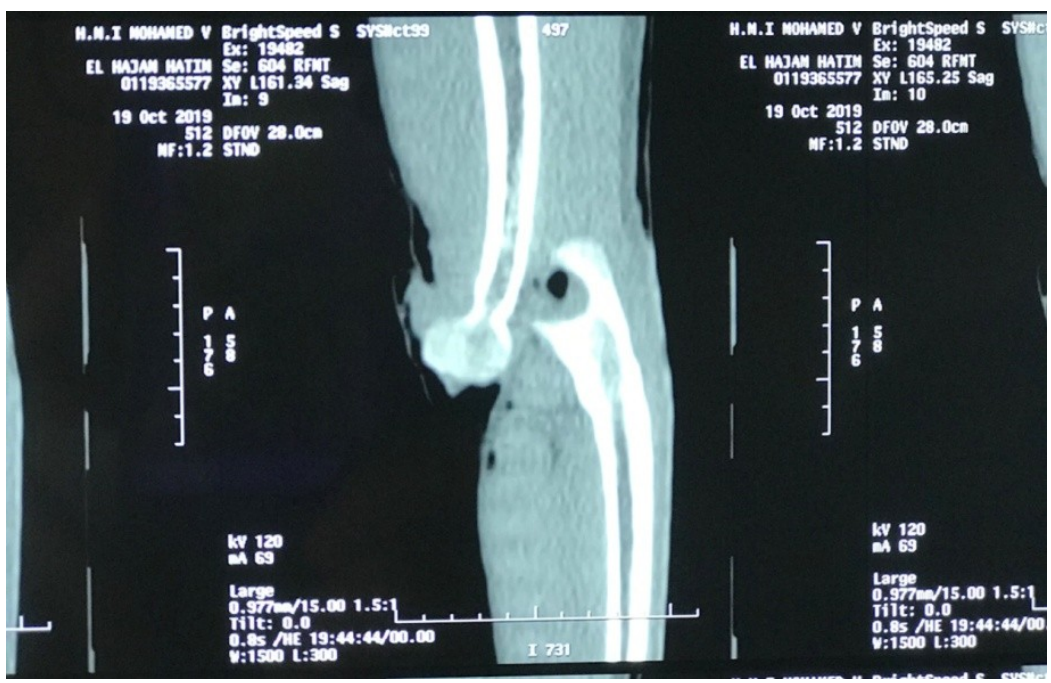

Figures 3:- Left elbow scanner showing a pure posterior dislocation.

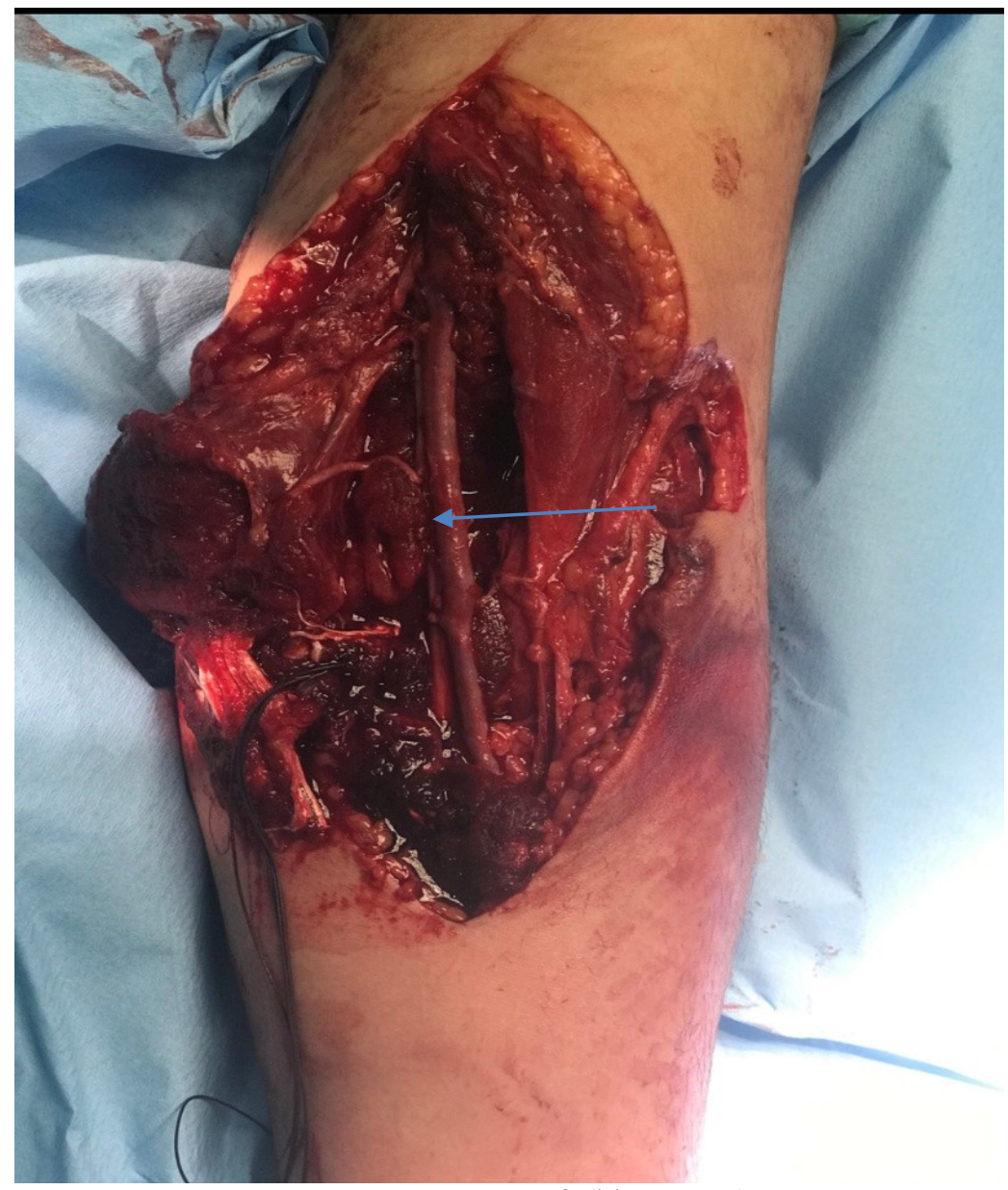

Figure 4:- Venous graft (blue arrow). 


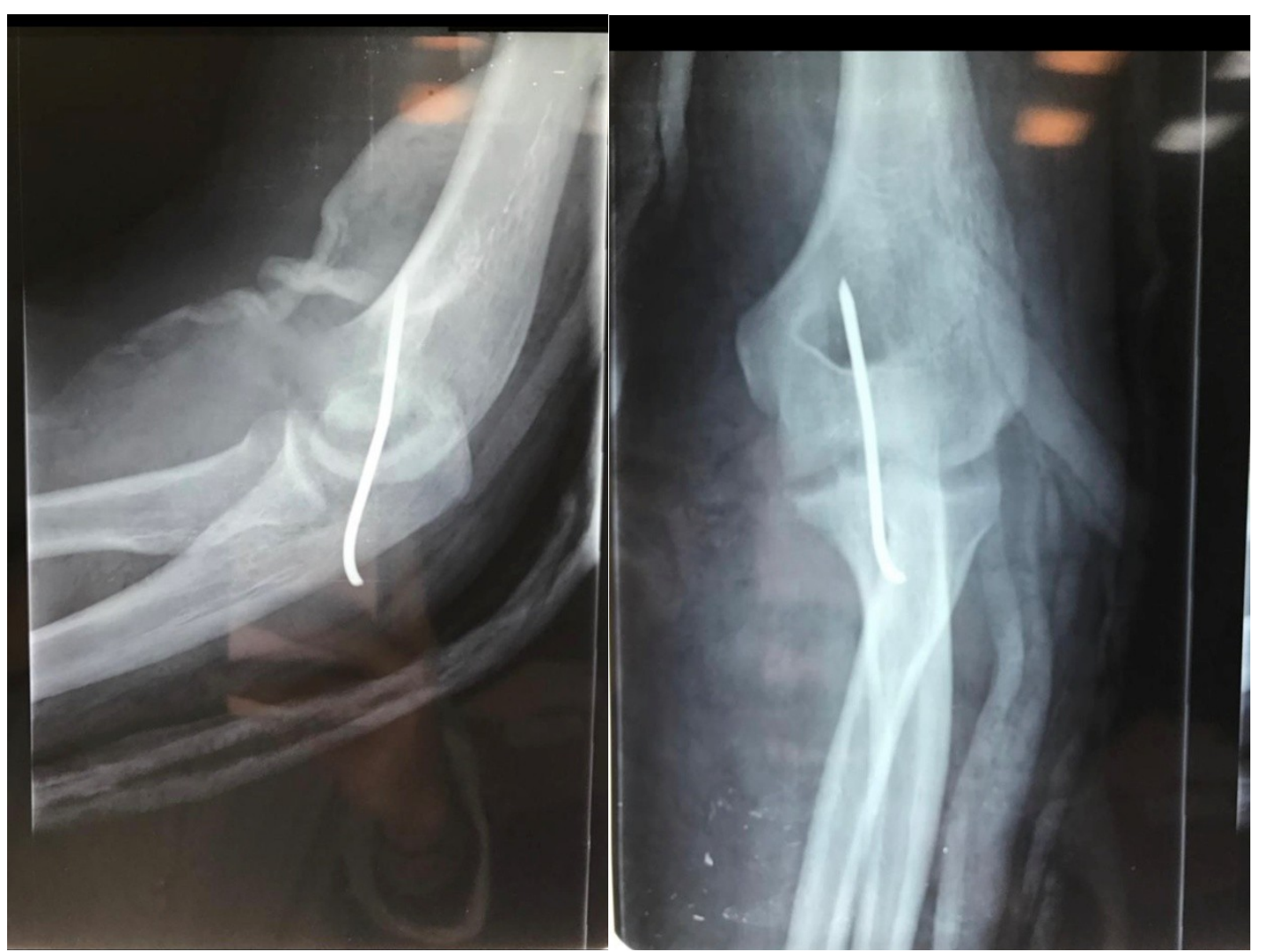

Figures 5:- Standard radio showing the humeral arthrosis.

\section{Conclusion:-}

Elbow dislocations remains frequent traumas, the mild nature of which is conditioned by the quality and consistency of care. The open nature of this dislocation without the presence of a fracture and its association with arterial involvement are exceptional. The search for signs of ischemia should be systematic before and after reduction. If there is any doubt, arteriography should be considered. Reducing emergency dislocation is the first step, with the obligation to obtain a stable elbow. Vascularrepairinvolvesvenous bypass

\section{References:-}

1. article Luxations du coude avec rupture de l'axe vasculaire. Étude critique d'une série de neuf cas J.-E. Ayela, N. Bonneviallea, J.-M. Lafosseb, L. Pidhorzc, M.A. Homsyc, P. Mansata, X. Chaufourd, M. Rongieresa, P. Bonneviallea

2. Endean ED, Veldenz HC, Schwarcz TH, Hyde GL. Recognition of arterial injury in elbow dislocation. J VascSurg 1992; 16:402-6.

3. Moneim MS, Garst JR. Vascular injuries associated with elbow fractures and dislocations. IntAngiol 1995; 14:307-12.

4. Sparks SR, Delarosa J, Bergan JJ, Hoyt DB, Owens EL. Arterial injury in uncomplicated upper extremity dislocations. Ann VascSurg 2000; 14:110-3.

5. Hildebrand KA, Patterson SD, King GJ. Acute elbow dislocations: simple and complex. OrthopClin 1999;30: $63-79$.

6. Josefsson PO, Johnell O, Wendeberg C. Ligamentous injuries in dislocations of the elbow joint. ClinOrthop 1987;221: 221-5.

7. Cohen MS, Hastings H. Acute elbow dislocation: evaluation and management. J AcadOrthopSurg 1998; 6:1523.

8. Carlioz H, Abols Y. Posterior dislocation of the elbow in children. J PediatrOrthop 1994; 4:8-12

9. Rasool MN. Dislocations of the elbow in children. J Bone Joint Surg Br $2004 ; 86$ :1050-6.

10. Josefsson PO, Johnell O, Gentz CF. Long term sequalae of simple dislocation of the elbow. J Bone Joint Surg Am 1984; 66:927-308. 
11. O'Driscoll SW. Classification and evaluation of recurrent instability of the elbow. ClinOrthop 2000; 370:3443.

12. Duckworth AD, Ring D, Kulijdian A, Mac Kee MD. Unstable elbow dislocation. J Shoulder Elbow Surg 2007.

13. Rignault D, Moine D. Rupture artériellehumérale par luxation du coude . Restauration vasculaire primitive. RevChirOrthop $1971 ; 57: 155-8$.

14. Louis DS, Ricciardi JE, Spengler DM. Arterial injury: a complication of posterior elbow dislocation. A clinical and anatomical study. J Bone Joint Surg Am 1974; 56:1631—6, 4.

15. Sturm JT, Rothenberger DA, Strate R. Brachial artery disruption following closed elbow dislocation. J Trauma 1978;18: $364-6$.

16. Hoffamann KE, Moneim MS, Omer GE, Ball WS. Brachial artery disruption following closed posterior elbow dislocation in a child - assessment with intravenous digital angiography. A case report with review of the literature. ClinOrthop 1984; 184:145-9.

17. Grimer RJ, Brooks S. Brachial artery damage accompanying closed posterior dislocation of the elbow. J Bone Joint Surg Br 1985; 67:378-81.

18. Manouel M, Minkowitz B, Shimotzu G, Haq I, Fellicia J. Brachial artery laceration with closed posterior elbow dislocation in an 8-year-old. ClinOrthop 1993; 296:109-12.

19. Slowik GM, Fitzimmons M, Rayhack JM. Closed elbow dislocation and brachial artery damage. J Orthop Trauma 1993; 7:558-61.

20. Seidman GD, Koerner PA. Brachial artery rupture associated with closed posterior elbow dislocation: a case report and review of the literature. J Trauma 1995; 38:318-21.

21. Baulot E, Giroux E, Ciry-Gomez M, Grammont PM. Brachialis arteria rupture following closed posterior elbow dislocation. Case report and literature review. Ann Chir Main 1997; 16:258—62. 